\title{
Chronic Distal Triceps Brachii Tendon Ruptures. A Systematic Review of Surgical Procedures and Outcomes
}

\author{
F. Oliva ${ }^{1}$, F. F. Sesti ${ }^{2}$, M. Gasparini ${ }^{2}$, L. Panarella ${ }^{2}$ \\ 1 Department of Orthopaedic and Trauma Surgery, University of Salerno School of Medicine Surgery and \\ Dentistry, Salerno, Italy \\ 2 Department of Orthopaedic and Traumatology, University of Rome 'Tor Vergata', Rome, Italy
}

\author{
CORRESPONDING AUTHOR: \\ Francesco Oliva \\ Department of Orthopaedic \\ and Trauma Surgery \\ University of Salerno \\ School of Medicine \\ Surgery and Dentistry \\ Salerno, Italy \\ E-mail: olivafrancesco@hotmail.com \\ DOI: \\ 10.32098/mltj.01.2020.01
}

LEVEL OF EVIDENCE: $3 A$

\begin{abstract}
SUMMARY
Background. Chronic and neglected ruptures of distal triceps brachii tendon (TBT), for different reasons, are rarer than acute ruptures. We aimed to review the literature about their surgical treatment and outcome to better understand how to address this kind of rare tendon injuries.

Sources of data. Published articles in English in PubMed, Scopus and Google Scholar up to December 2019 about chronic ruptures of distal TBT. Twenty-one papers were included following the Preferred Reporting Items for Systematic Reviews and Meta-Analyses (PRISMA) guidelines. Areas of agreement. In cases of neglected rupture or re-rupture of the distal TBT surgical treatment is required.

The macroscopic quality of the residual stump rather than the timing of intervention is the key point in the choice of a specific surgical procedure, included autograft or allograft.

Areas of controversy. Several surgical procedures are described to restore the tendon anatomy and function. The quality of the current literature could not afford definitive conclusions on which procedure guarantee the best results.

Growing points. Studies comparing different surgical treatments need to be further investigated. If found to be significant, preventive and therapeutic strategies should subsequently be developed.
\end{abstract}

KEY WORDS

Distal Triceps Brachii Tendon; rupture; rerupture; inveterated rupture; chronic rupture; surgery

\section{INTRODUCTION}

The distal TBT rupture is a rare injury. Most of the case series reported are sport-related, the main mechanism seems due to uncoordinated contraction of the triceps against flexed elbow such as from a fall on an outstretched arm, or for a direct trauma on elbow with associated open or closed fracture (1). Although a trauma is often described in the past medical history, intrinsic predisposing factors for tendon ruptures are well know such as: rheumatoid arthritis, systemic lupus erythematosus, hyperparathyroidism, diabetes mellitus, chronic renal disease and they need to be investigated in each patient (2-5). Regarding drugs related injuries fluoroquinolones (6), anabolic steroids $(7,8)$ and local steroids injections are considered iatrogenic causes of TBT ruptures.
Distal TBT rupture may involve different anatomical regions: a) proximally at the origin of the lateral head of the triceps, b) at the triceps muscle belly, c) at the musculotendinous junction, $\mathrm{d}$ ) in the tendon per se, or e) an avulsion from the bony footprint of the olecranon (9-11).

The diagnosis is merely clinical; the mechanism of injury may help to consider it. Bruising and swelling along the posterior aspect of arm with limited or lack of extension are the main symptoms. In some patients, a palpable gap at the rupture site may be present. It is reported that several patients did not receive a diagnosis on initial assessment (12). The missed diagnosis is the main cause of delayed intervention and neglected tendon tears. Radiographs of the elbow allowed to find flecks of avulsed osseous mate- 
rial from the olecranon or to classify associated fractures. A computed tomography scan can be helpful in excluding associated bony injuries. Magnetic resonance imaging (MRI) and ultrasounds are useful in those patients in whom the lesion is partial (13). The complete tear features by large fluid-filled gap in the T2-weighted image between the retracted stump of the TBT and the olecranon (14). MRI is useful to assess muscle quality, especially for chronic ruptures, and may help determine if a graft procedure is required (15). The treatment of the acute ruptures of distal TBT is well established $(1,16)$. A chronic rupture of a tendon can be defined as a rupture with a delay in diagnosis or treatment for more than 6 weeks. Specifically for distal TBT ruptures has been observed that the degenerative evolution of the tendon occurred slower than other tendon ruptures such as those affecting the Achilles tendon (17). When muscle-tendon retraction is caused by delayed diagnosis or when the remaining available tissue is limited because of previous surgery or infection, the direct sutures techniques are not feasible. Therefore, different augmentation procedures have been developed, which allowed theoretically rebuilding of the elbow extensor mechanism (6-12). There is lack of prospective randomized trials due to small sample of patients for these procedures thus their results do not lead to a standard surgical treatment.

At this insertion the triceps width is $2.6 \pm 0.5 \mathrm{~cm}$ (standard deviation), and the triceps lateral retinaculum extends the tendon laterally for $2.5 \pm 0.7 \mathrm{~cm}$. The tendinous portion of the triceps tendon extends proximally $15.3 \pm 1.4 \mathrm{~cm}$. The triceps inserts at a mean of $1.1 \mathrm{~cm}$ from the tip of the olecranon (18).

In case of chronic ruptures of distal TBT we observed different approach by authors not only in the choice of the graft but even in the indication of specific procedure. For example, Singh et al. used the extensor carpi radialis longus and palmaris longus tendon grafts in a case of $7 \mathrm{~cm}$ gap (19). Wagner et al. used the plantaris tendon in a case of $4 \mathrm{~cm}$ gap (11).

For the mentioned reasons we performed a review of the literature about the treatment of the chronic, neglected and re-ruptures of distal TBT. To our knowledge, no systematic review of such studies has been conducted to clarify the best surgical procedures and outcomes.

\section{METHODS}

The meta-Analysis and its procedures were organized, conducted and reported following the Preferred Reporting Items for Systematic Reviews and Meta-Analyses (PRISMA) guideline (20).
Our PRISMA checklist is presented in an online supplement (figure 1). We wished to try to assess:

- risk of factor for chronic of distal TBT ruptures;

- surgical procedures;

- post-surgical outcomes and complications;

- return to sport or daily activity.

We performed a meta-analysis of the literature about the treatment of chronic and re-ruptures of distal TBT. We included case series and case reports. We excluded: acute ruptures cases, reviews and studies on cadaveric specimen and animal models.

\section{SOURCE OF STUDIES AND SEARCH STRATEGY}

We performed a systematic search (up to December 2019) in the PubMed, Scopus and Google Scholar electronic databases of articles concerning the chronic and re-ruptures of distal TBT and the surgical techniques, published in English only. The search strategy covered all the cases of TBT chronic ruptures surgically treated. In addition, we recorded complications and functional outcomes. In the search strategy, we used different combinations of the following key terms and MesH terms: Triceps Brachii Tendon, rupture, re-rupture, inveterate rupture, neglected rupture, chronic rupture, delayed rupture, surgery.

We considered chronic ruptures from 60 days after the injury. We only considered for inclusion in the present meta-analysis published articles that had considered the association between surgery and chronic rupture in humans.

\section{STUDY SELECTION AND ELIGIBILITY CRITERIA}

Two orthopedic residents performed the search and evaluated the articles independently. A researcher experienced in systematic reviews solved cases of doubt. At the beginning of the procedure, each examiner read the abstracts of all the articles, selected the relevant ones according to inclusion and exclusion criteria previously determined, and then compared the results with the other examiner. After 4 weeks, the same studies were read again to establish the agreement of the researchers on the selection. No disagreement was observed among the investigators.

\section{DATA COLLECTION}

One reviewer extracted the data from the full-text articles to Excel spreadsheet structured tables to analyze 

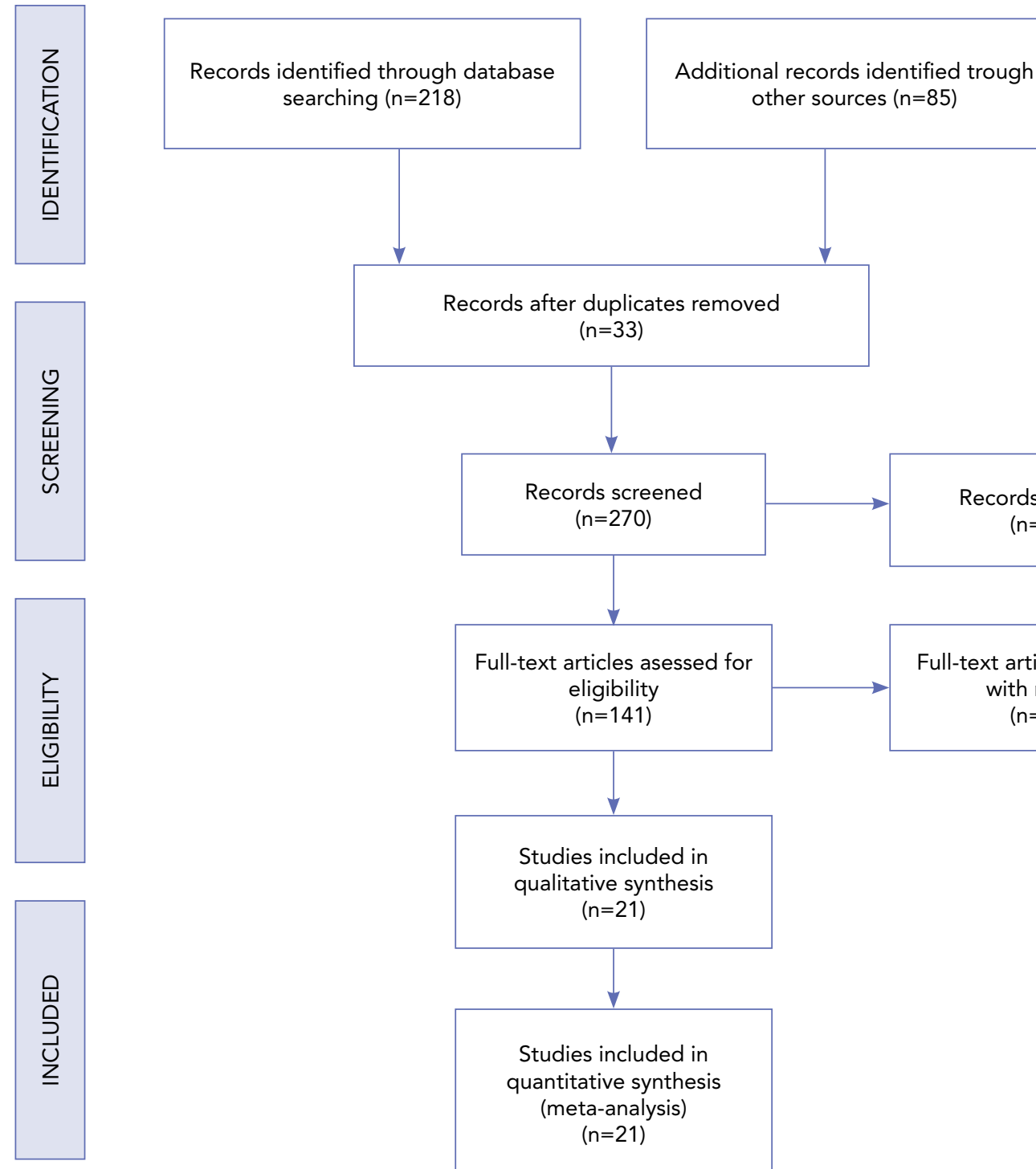
other sources $(n=85)$

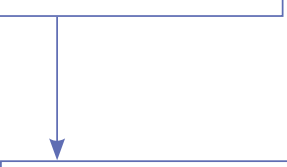

Records after duplicates removed $(n=33)$

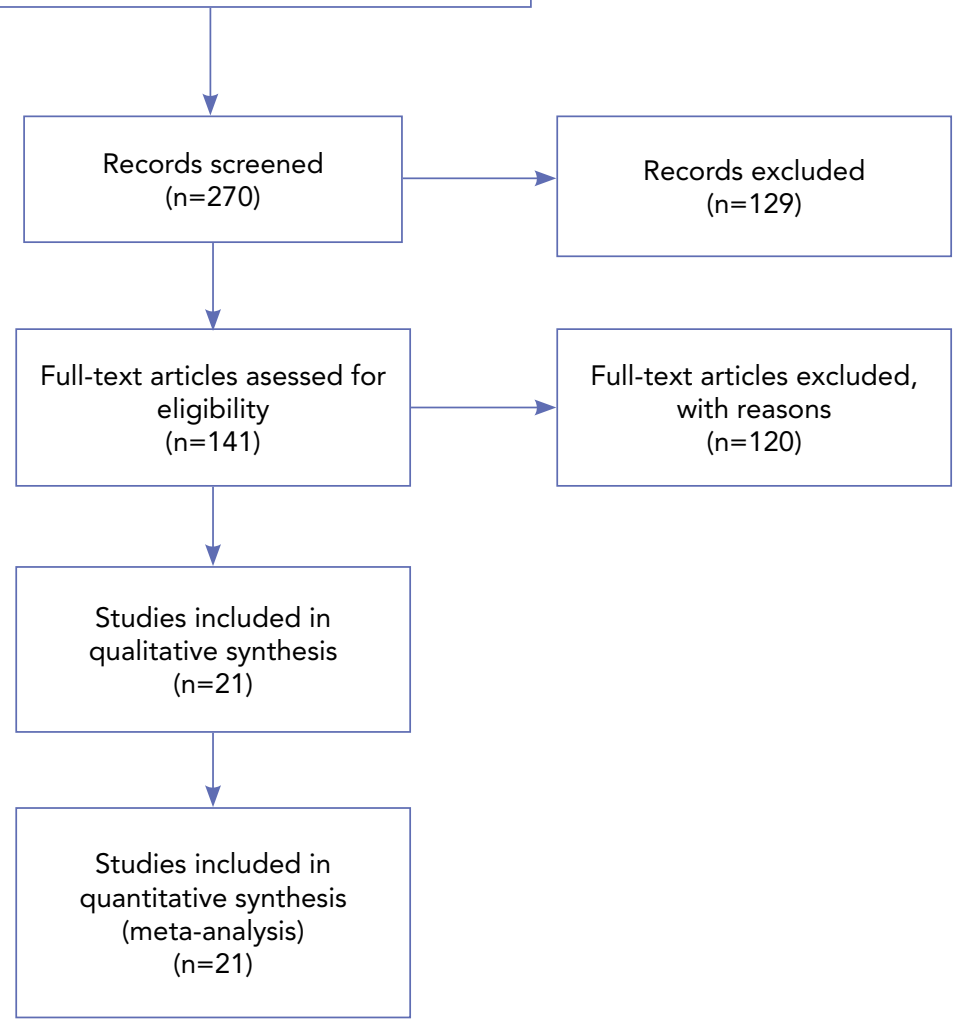

Figure 1. PRISMA flow diagram 2009.

the study in a descriptive fashion. The second researcher independently double checked the extraction of primary data from all the articles. Doubts and inconsistencies were followed and solved by discussion. The following information was extracted from articles: mechanism of injury, mean range time before surgery, type of lesion/re-rupture, associated injuries and comorbidities, type of surgery, muscle strength recovered after surgery, complications.

\section{RESULTS}

After our initial literature search, a total of 303 potentially relevant citations were identified. After removal of duplicates, 270 articles remained. Title and abstract review excluded an additional 129 articles about the basis of the irrelevant pathology or non-English language. A total of 21 articles were eventually included in the present review. Each of them used different surgical procedures and different 


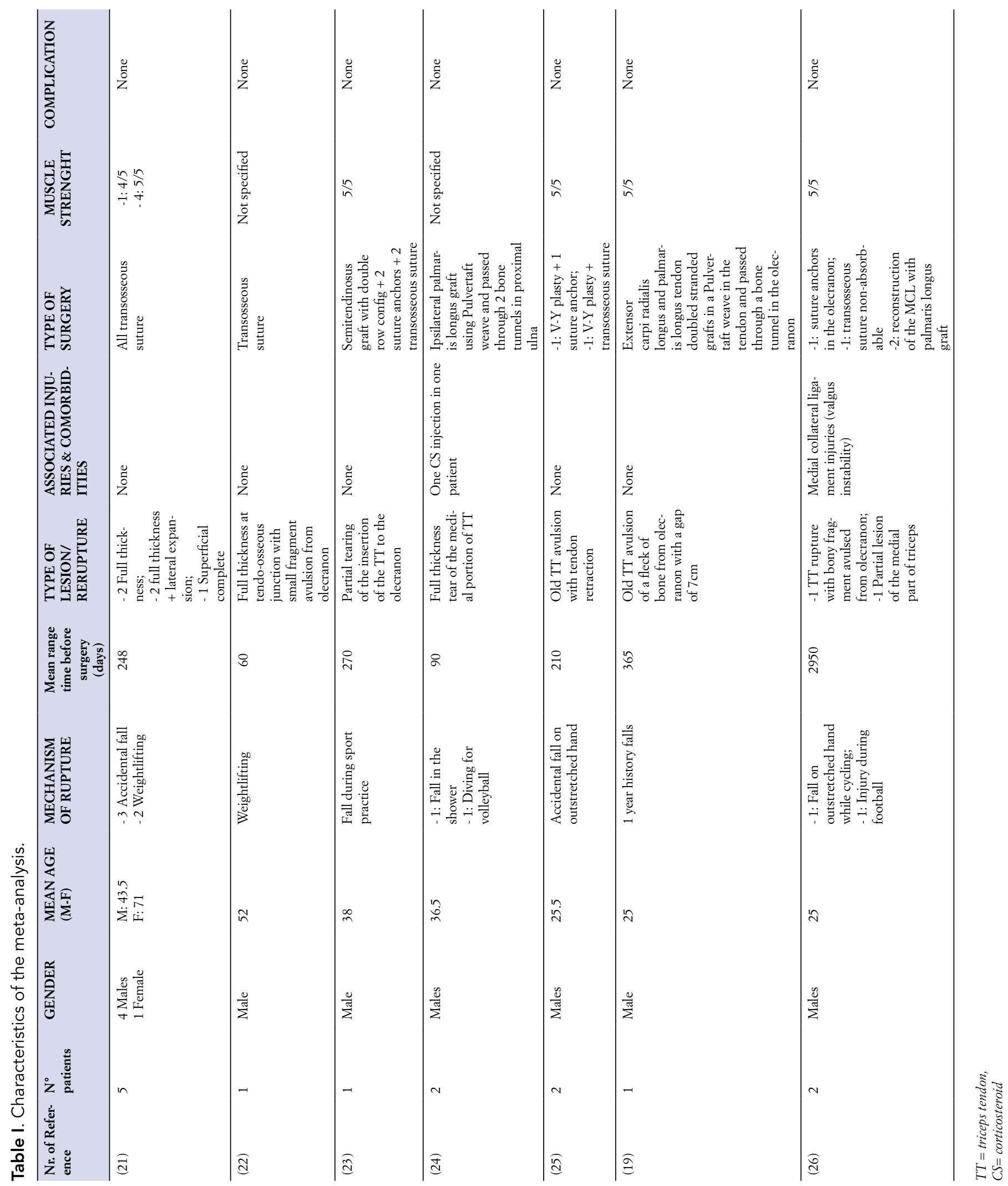




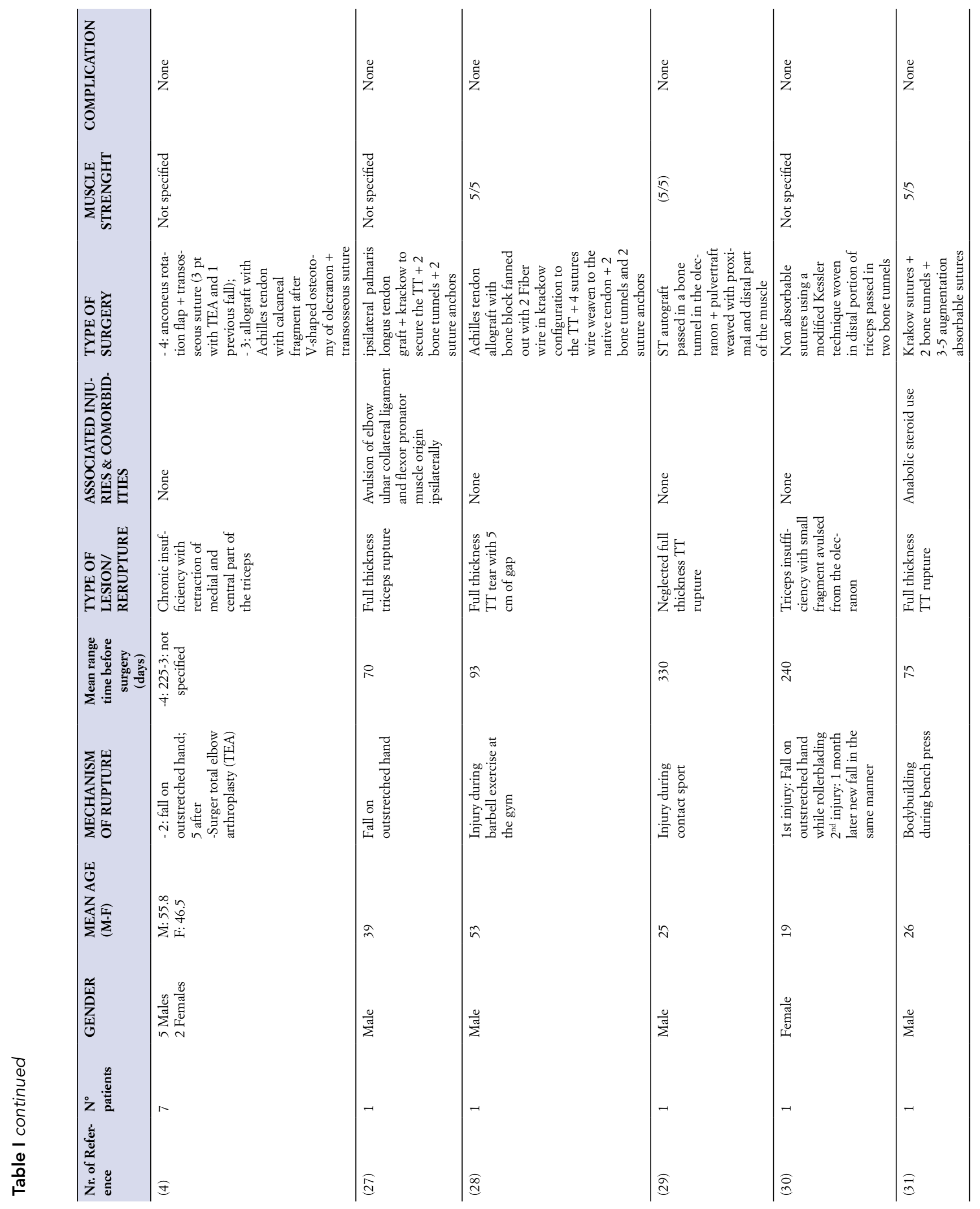

Muscles, Ligaments and Tendons Journal 2020;10 (1) 


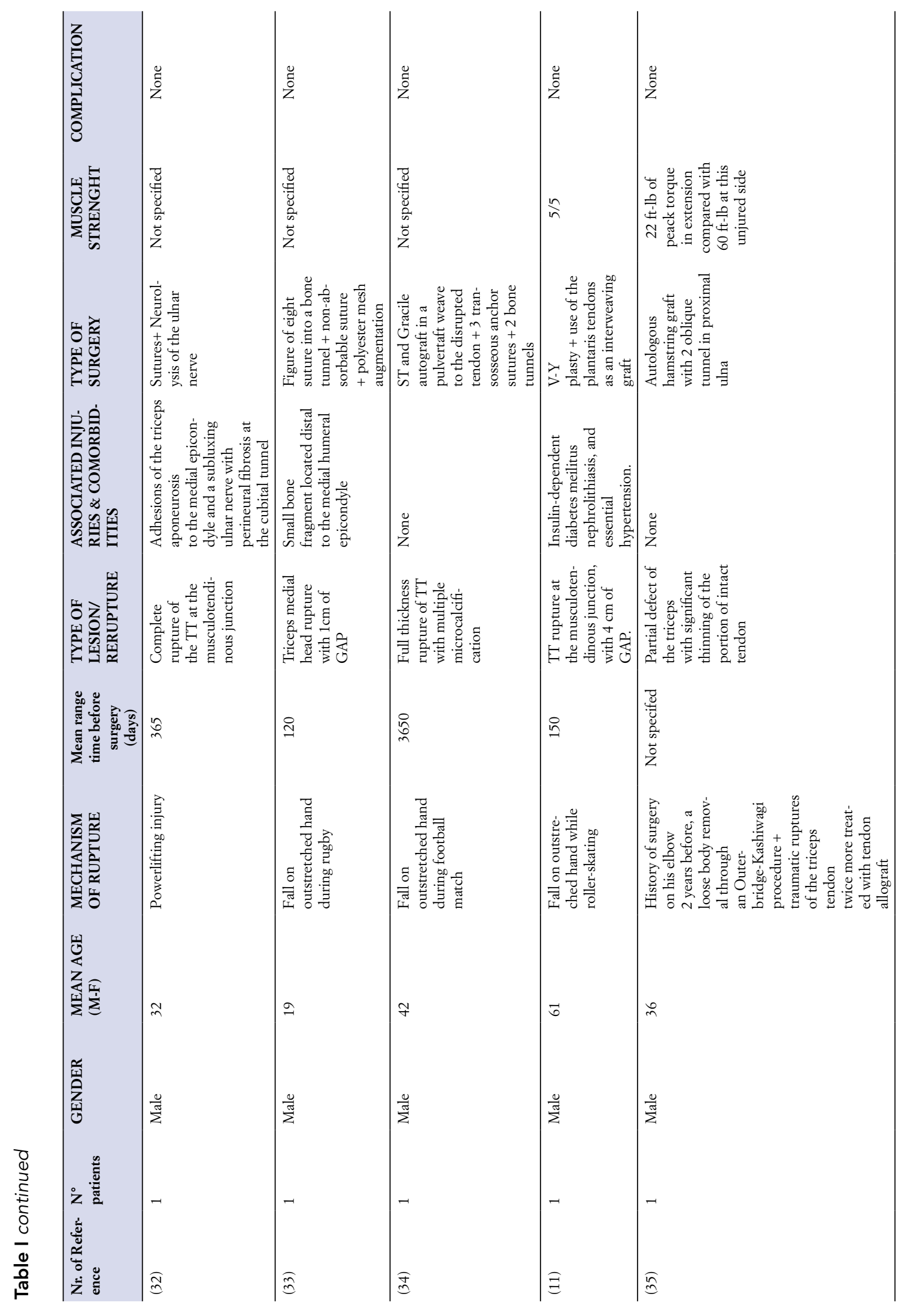




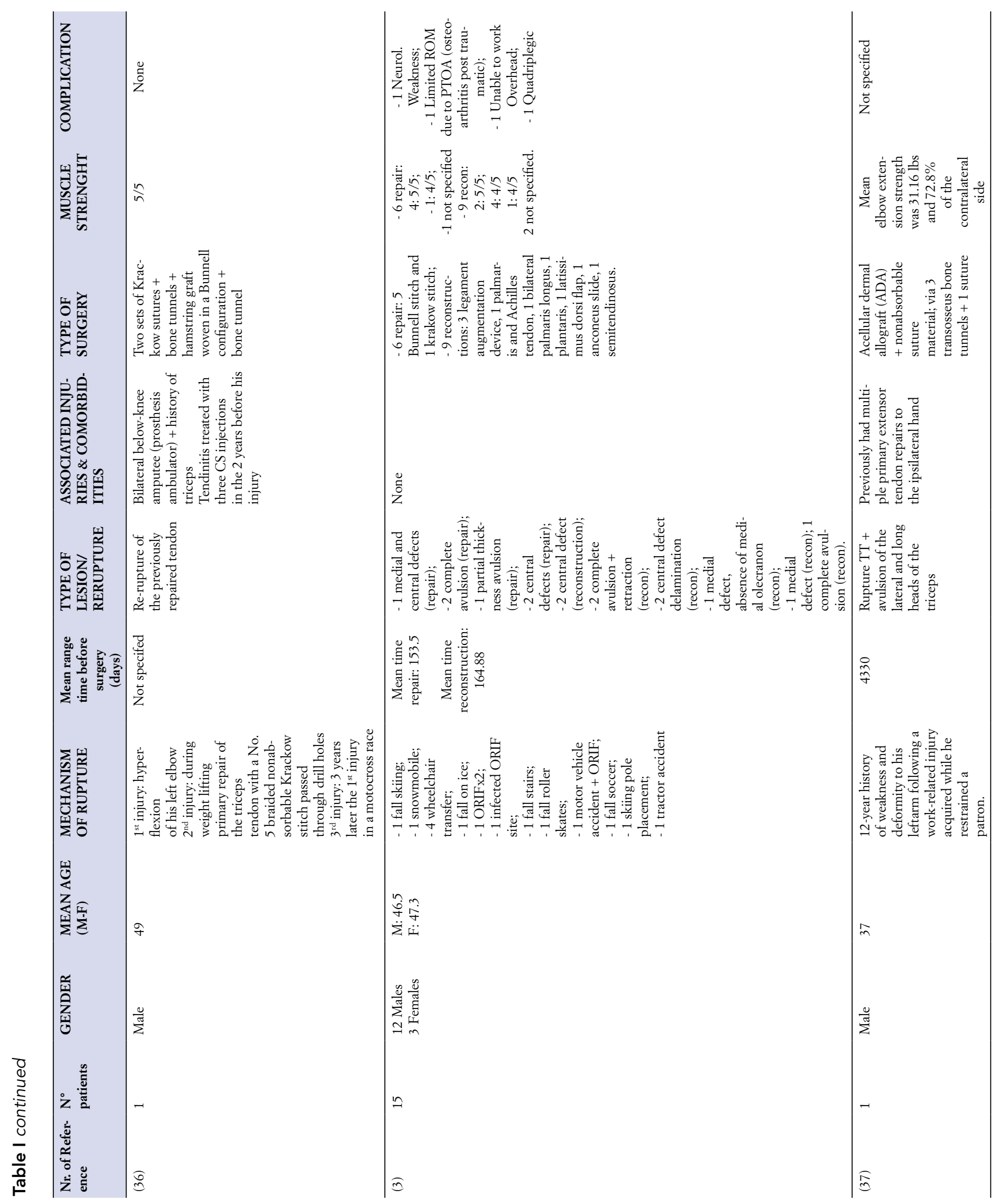


protocols, making statistical data analysis impossible. Study selection, retrieval and inclusion and exclusion reasons are shown in the flowchart above (figure 1). The number of the reference, the methods and the data collected from the included articles are shown in the table I.

This systematic review included forty-eight patients.

\section{DISCUSSION}

\section{Risk of factor for re-rupture of the triceps tendon}

A medical history is important to make the right diagnosis and the best decision. Risk factors found, were: male gender $(85 \%)$ with mean age of 37 years old while females patients were older (mean age of 45 years old), metabolic disease $(2 \%)$, anabolic steroid use $(2 \%)$, local injections of corticosteroid $(6 \%)(5,7)$, sports such as weight lifting, skiing, football, rugby, volleyball $(45 \%)$ or those sports that cause an elbow stress. (38) Testosterone administration can lead to alterations of biomechanical properties of tendons (39), reduction of elastic properties (40), tendon dysfunction and fibrosis, with a higher incidence of spontaneous tendon ruptures (41).

Other associated lesions of the medial compartment were found $(10 \%)$ and comorbidities like diabetes mellitus (2\%) and nephrolithiasis (2\%).

The most frequent mechanism of injury was a fall on outstretched hand $(21 \%)$ especially during contact sport or an unsuitable movement during weight lifting.

\section{Type of lesion or re-rupture}

The distal TBT ruptures found were: at the muscle-tendinous junction $(4.1 \%)$, partials ruptures $(31.2 \%)$, full-thickness ruptures $(41.6 \%)$, avulsion $(20.8 \%)$ and re-ruptures $(2 \%)$. Paniago et al.(23) used a semitendinosus (ST) autologous graft 270 days after the injury, McMillian et al. treated a rupture after 90 days, while Herrick et al.(32) only used direct sutures one year after. Thus we observed that there was no relation between time of surgery and use of graft. The quality of the distal stump after removing all the calcification and the non-healing tissue resulted the most important factor that contributed to the choice of the surgical technique.

The signs of macroscopic bad quality of residual tendon stump as degenerations and calcifications $(23,24,28,34)$, large loss of tendon substance $(19,29)$ are the main features which suggest the use of a grafts.

\section{Surgical procedures}

In this meta-analysis we found that in the $45 \%$ of patients was used a graft (autograft or allograft). Furthermore, we found use of trans-osseous sutures $(69 \%)$, suture anchors $(27 \%)$, anconeus flaps $(5 \%)$ and V-Y technique $(6 \%)$ often in combined manner (24).

The autologous semitendinosus (ST) graft was the most used: Weistroffer et al. used this graft in one patient affected by a re-rupture (36) whereas other authors used it in patients with a chronic lesion $(23,29,34,35)$. While Singh et al. preferred extensor carpi radialis longus and palmaris longus tendon in a doubled stranded grafts (19), Wagner et al. performed an augment after a distal TBT rupture with the plantaris tendon (11) and Scolaro et al. preferred only ipsilateral palmaris longus in two chronic distal TBT ruptures (24). McMillian et al. and Sanchez - Sotelo et al. used an allograft of Achilles tendon in 4 patients with large deficiency of TBT and an anconeus flap in one patient with moderate deficiency $(4,28)$. Among allografts, the Achilles tendon is the most used and its availability avoids the risks associated with the harvest of an autograft. Among autografts, the ST graft has superior strength, cross-sectional area and length (36) then the other autologous grafts.

\section{Post-surgical outcomes and complications}

In this meta-analysis twenty-one $(44 \%)$ patients recovered all muscle strength, six patients (12\%) recovered $4 / 5$ muscle strength and two had deficit of strength. In eight patients, the muscle strength at the follow-up was not reported. This is important and it might be a parameter of treatment efficacy. Sollender et al. found that all patients were able to resume normal activities, although to minimal residual weakness of elbow extension compared to the contralateral elbow (7). In one case Biodex testing showed $22 \mathrm{ft}-1 \mathrm{~b}$ of peak torque in extension, compared to $60 \mathrm{ft}-\mathrm{lb}$ on his uninjured side (35).

We suggest using scores as DASH or ULFI score in order to compare the efficacy of the different types of treatment. We found that surgical procedures in chronic distal TBT repair might have more complications than acute surgical repair. For example as a $10^{\circ}$ terminal restriction of elbow flexion (42), a $5^{\circ}$ extension loss, ulnar nerve entrapment, confirmed with EMG, posterior interosseous nerve palsy occurred in one patient who underwent simultaneous radial head fracture fixation, but regained its normality after 3 months postoperatively (31), olecranon bursitis (43), wound infection. One patient was dissatisfied at the end of the follow-up (16).

\section{CONCLUSIONS}

This systematic meta-analysis has some limitations. All the included studies were case reports and case series, therefore the level of evidence was low. This could be justified by 
the rarity of the injury. The latter consideration limited final recommendations but highlighted the necessity for higher level studies comparing non-surgical and surgical treatment to produce definitive recommendations and different type of surgery. However, for relatively infrequent conditions such as chronic distal TBT ruptures, accumulation of a moderate volume of level IV evidence as presented in this systematic review may be sufficient for recommend surgical treatment for patients with appropriate clinical and imaging characteristics. There was also slight uniformity in patient demographics, treatment protocol, and outcome reporting. Finally, in some studies, the raw data concerning range of motion and/ or strength were absent, so stratification into the satisfac-

\section{REFERENCES}

1. Tom JA, Kumar NS, Cerynik DL, Mashru R, Parrella MS. Diagnosis and Treatment of Triceps Tendon Injuries: A Review of the Literature: Indian J Ortho 2014;24(3):197-204.

2. McCulloch PC, Spellman J, Bach BR. Familial triceps tendon ruptures. Orthopedics. 2008;31(6):600-2.

3. Van Riet RP, Morrey BF, Ho E, O’Driscoll SW. Surgical treatment of distal triceps ruptures. J Bone Jt Surg - Ser A. 2003;85(10):1961-7.

4. Sanchez-sotelo J, Morrey BF. Surgical techniques for recostruction of chronic insufficiency of the triceps. Rotation flap using anconeus and tendo achillis allograft. J Bone Joint Surg Br. 2002;1116-20.

5. Tsourvakas S, Gouvalas K, Gimtsas C, Tsianas N, Founta P, Ameridis N. Bilateral and simultaneous rupture of the triceps tendons in chronic renal failure and secondary hyperparathyroidism. Arch Orthop Trauma Surg. 2004;124(4):278-80.

6. Godoy-Santos AL, Bruschini H, Cury J, Srougi M, de Cesar-Netto C, Fonseca LF, et al. Fluoroquinolones and the Risk of Achilles Tendon Disorders: Update on a Neglected Complication. Urology. 2018;113:20-5.

7. Sollender JL, Rayan GM, Barden GA. Triceps tendon rupture in weight lifters. J Shoulder Elb Surg. 1998;7(2):151-3.

8. Mair SD, Isbell WM, Gill TJ, Schlegel TF, Hawkins RJ. Triceps Tendon Ruptures in Professional Football Players. Vol. 32, American Journal of Sports Medicine. 2004. 431-4.

9. Madsen M, Marx RG, Millett PJ, Rodeo SA, Sperling JW, Warren RF. Surgical anatomy of the triceps brachii tendon: anatomical study and clinical correlation. Am J Sports Med. 2006;34(11):1839-43.

10. Keener JD, Chafik D, Kim HM, Galatz LM, Yamaguchi K. Insertional anatomy of the triceps brachii tendon. J shoulder Elb Surg. 2010;19(3):399-405.

11. Wagner JR, Cooney WP. Rupture of the triceps muscle at the musculotendinous junction: A case report. J Hand Surg Am. 1997;22(2):341-3.

12. Ganeshan RM, Keerthi N. Isolated medial head of triceps rupture. BMJ Case Rep. 2014;2014:1-3.

13. Tarallo L, Zambianchi F, Mugnai R, Costanzini CA, Catani F. Distal triceps tendon repair using Krakow whipstitches, $\mathrm{K}$ wires, tension band and double drilling technique: A case report. J Med Case Rep. 2015;9(1):1-4. tion category was deduced using author's descriptors rather than objective data. We suggest to use autografts, in case of bad quality of the stump with a gap over $3 \mathrm{~cm}$ rather than allografts because are cheaper and always available. Among autografts, the use of ST allowed good outcomes. Without comparative studies it is impossible conclude which is the best procedure. We try to support more scientific evidence in the choice of the surgical procedures, standard outcome scales and rehabilitation protocols.

\section{CONFLICT OF INTERESTS}

The authors declare that they have no conflict of interests.
14. Kholinne E, Al-Ramadhan H, Bahkley AM, Alalwan MQ, Jeon IH. MRI overestimates the full-thickness tear of distal triceps tendon rupture. J Orthop Surg. 2018;26(2):1-5.

15. Hughes RE, Schneeberger AG, An KN, Morrey BF, O'Driscoll SW. Reduction of triceps muscle force after shortening of the distal humerus: a computational model. J Shoulder Elbow Surg. 1997;6(5):444-8.

16. Kokkalis ZT, Mavrogenis AF, Spyridonos S, Papagelopoulos PJ, Weiser RW, Sotereanos DG. Triceps Brachii Distal Tendon Reattachment With a Double-row Technique. Harwin SF, editor. Orthopedics. 2013;36(2):110-6.

17. Maffulli N, Via AG, Oliva F. Chronic Achilles Tendon Rupture. Open Orthop J. 2017 8;11(1):660-9.

18. Barco R, Sánchez P, Morrey ME, Morrey BF, Sánchez-Sotelo $\mathrm{J}$. The distal triceps tendon insertional anatomy-implications for surgery. JSES Open Access 2017;1(2):98-103.

19. Singh D, Arun Kumar K, Dinesh MC, Raj R. Chronic triceps insufficiency managed with extensor carpi radialis longus and palmaris longus tendon grafts. Indian J Orthop. 2012;46(2):236-8.

20. Moher D, Liberati A, Tetzlaff J, Altman DG, Group TP. Linee guida per il reporting di revisioni sistematiche e meta-analisi : il PRISMA Statement. Evidence. 2015;7(6).

21. Giannicola G, Bullitta G, Rotini R, Murena L, Blonna $D$, Iapicca $M$, et al. Results of primary repair of distal triceps tendon ruptures in a general population. Bone $\mathrm{Jt} \mathrm{J}$. 2018;100B(5):610-6.

22. Mangano T, Cerruti P, Repetto I, Trentini R, Giovale M, Franchin F. Chronic Tendonopathy as a Unique Cause of Non Traumatic Triceps Tendon Rupture in a (Risk Factors Free) Bodybuilder: A Case Report. Journal of orthopaedic case reports. 2015. 58-61.

23. Paniago AF, Storti TM, Faria RSS, Morais DCA de, Souza MP de. Reconstruction of chronic tearing of the distal triceps using the double-row configuration: technical note. Rev Bras Ortop. 2015;50(5):596-600.

24. Scolaro JA, Blake MH, Huffman GR. Triceps tendon recostruction using ipsilateral palmaris longus autograft in unrecognized chronic tears. Orthopedics 2013;36(1):117-20.

25. Yazdi HR, Qomashi I, Ghorban Hoseini M. Neglected triceps tendon avulsion: case report, literature review, and a new 
repair method. Am J Orthop (Belle Mead NJ). 2012;41(7) : E96-941.

26. Tatebe M, Horii E, Nakamura R. Chronically ruptured triceps tendon with avulsion of the medial collateral ligament: A report of 2 cases. J Shoulder Elb Surg. 2007;16(1):e5 -7.

27. Daglar B, Delialioglu OM, Ceyhan E, Altas O, Bayrakci K, Gunel U. Combined surgical treatment for missed rupture of triceps tendon associated with avulsion of the ulnar collateral ligament and flexor-pronator muscle mass. Strateg Trauma Limb Reconstr. 2009;4(1):35-9.

28. Mc Millan S. Case Report: Delayed Surgical Reconstruction with an Achilles Tendon Allograft for Triceps Tendon Rupture: Technique and Results. MOJ Orthop Rheumatol. 2015;3(6):3-6.

29. Gupta RK, Soni A, Malhotra A, Masih GD. Journal of Clinical Orthopaedics and Trauma Triceps tendon reconstruction using autologous semitendinosis graft in professional kabaddi player - A rare case report. J Clin Orthop Trauma. 2017;8:S38-40.

30. Inhofe PD, Moneim MS. Late presentation of triceps rupture. A case report and review of the literature. American journal of orthopedics (Belle Mead, N.J.). 1996, 25 (11):790-2.

31. Kose O, Kilicaslan OF, Guler F, Acar B, Yuksel HY. Functional outcomes and complications after surgical repair of triceps tendon rupture. Eur J Orthop Surg Traumatol. 2015;25(7):1131-9.

32. Herrick RT, Herrick S. Ruptured triceps in a powerlifter presenting as cubital tunnel syndrome. A case report. Am J Sport Med. 1987;514-6.

33. Sai S, Fujii K, Chino H, Inoue J, Ishizaka J. Old rupture of the triceps tendon with unique pathology: A case report. J Orthop Sci. 2004;9(6):654-6.

34. Dos Remedios C, Brosset T, Chantelot C, Fontaine C. Repair of a triceps tendon rupture using autogenous semi-tendinous and gracilis tendons. A case report and retrospective chart review. Chir Main. 2007;26(3):154-8.

35. Wolf JM, McCarty EC, Ritchie PD. Triceps Reconstruction Using Hamstring Graft for Triceps Insufficiency or Recurrent Rupture. Tech Hand Up Extrem Surg. 2008;12(3):1749.

36. Weistroffer CDRJK, Mills WJ, Shin AY, Diego S. Recurrent rupture of the triceps tendon repaired with hamstring tendon autograft augmentation : A case report and repair technique. J Shoulder Elb Surg. 2003;12(2):193-6.

37. Gouk CJC, Shulman RM, Buchan C, Taylor FJ. Chronic Distal Triceps Rupture Repaired Using Acellular Dermal Allograft as an Interposition Graft. Tech Shoulder Elb Surg. 2019;20(1):35-8.

38. Kokkalis ZT, Ballas EG, Mavrogenis AF, Soucacos PN. Distal biceps and triceps ruptures. Injury. 2013;44(3):318-22.

39. Marqueti RC, Parizotto NA, Chriguer RS, Perez SEA, Selistre-de-Araujo HS. Androgenic-Anabolic Steroids Associated With Mechanical Loading Inhibit Matrix Metallopeptidase Activity and Affect the Remodeling of the Achilles Tendon in Rats. Am J Sports Med. 2006;34(8):1274-80.

40. Miller BF, Olesen JL, Hansen M, Døssing S, Crameri RM, Welling RJ, et al. Coordinated collagen and muscle protein synthesis in human patella tendon and quadriceps muscle after exercise. J Physiol. 2005;567(3):1021-33.

41. Oliva F, Piccirilli E, Berardi AC, Frizziero A, Tarantino U, Maffulli N. Hormones and tendinopathies: The current evidence. Br Med Bull. 2016;117(1):39-58.

42. Jaiswal A, Kacchap N-D, Tanwar Y-S, Kumar D, Kumar B. Rupture of the triceps tendon - A case series. Chinese J Traumatol 2016;19(4):235-8.

43. Heikenfeld R, Listringhaus R, Godolias G. Endoscopic Repair of Tears of the Superficial Layer of the Distal Triceps Tendon. Arthrosc J Arthrosc Relat Surg. 2014;30(7):785-9. 